\title{
The B'Active programme for overweight primary school children in Glasgow: determining the prevalence of overweight and obesity and piloting an activity intervention
}

\author{
Adrienne R. Hughes ${ }^{1 *}$, Ruth McLaughlin ${ }^{2}$, Jane Mckay $^{2}$, Kevin Lafferty ${ }^{3}$, Tony McKay ${ }^{4}$ \\ and Nanette Mutrie ${ }^{2}$ \\ ${ }^{1}$ Division of Developmental Medicine, University of Glasgow, Glasgow, UK \\ ${ }^{2}$ Department of Sport, Culture and the Arts, University of Strathclyde, UK \\ ${ }^{3}$ Greater Glasgow Health Board, Glasgow, UK \\ ${ }^{4}$ Education Services, Glasgow City Council, Glasgow, UK
}

(Received 22 March 2006 - Revised 22 August 2006 - Accepted 22 August 2006)

\begin{abstract}
The aim of this study was to determine the prevalence of overweight and obesity in primary school children in Glasgow and to evaluate a pilot activity programme for overweight and obese children. BMI was measured in 1548 children. Overweight, obesity and severe obesity were defined as $\mathrm{BMI} \geq 85$ th, 95th and 98th centile, respectively. Overweight and obese children were then invited to participate in a 10-week school-based activity programme. The programme was evaluated by recording weekly attendance, intensity (using the Children's Effort Rating Scale) and enjoyment (scale 1-10). Focus groups were used to explore the experiences and views of the children, teachers, coaches and parents. Of the 1548 children, $31.4 \%$ were overweight, $19.1 \%$ were obese and $12.4 \%$ were severely obese; $38 \%$ of those invited attended the activity programme. Weekly programme attendance was $83 \%$ (range 56-99\%). Mean enjoyment rating (scale 1-10) was 8 for boys and 9 for girls. The intensity of activity sessions were rated 'very easy' by boys and 'just feeling a strain' by girls. Common themes emerging from the focus groups related to perceived positive and negative aspects of the programme (fun, concerns about stigmatising children); physical and psychological outcomes (fitter, more confident); and future recommendations (involve parents). In summary, the prevalence of overweight and obesity was high. The activity programme was successful in terms of attendance and enjoyment, and overall views of the initiative were positive and there was compelling support for its continuation.
\end{abstract}

Overweight: Obesity: Children: Intervention: Physical activity

The prevalence of overweight and obesity in children is increasing rapidly and overweight is now one of the most common paediatric health problems in the developed world. In England, the frequency of overweight in children ranged from $22 \%$ at age 6 to $31 \%$ at age 15 years and obesity ranged from $10 \%$ at age 6 to $17 \%$ at age 15 years (Reilly \& Dorosty, 1999). Recent Scottish prevalence data estimated that $23 \%$ of children aged $7-8$ years were overweight (BMI $>85$ th centile), which rose to $33 \%$ for children aged 11-12 years (NHS Scotland, 2003). The prevalence of obesity (BMI $>95$ th centile) was $11.5 \%$ in $7-8$ years-olds and $18 \%$ in 11-12-year-olds.

Paediatric overweight has significant adverse effects on physical and psychosocial health in childhood and adulthood (Reilly et al. 2003). Overweight children frequently experience psychological problems including depression, poor selfesteem and low body image (Reilly et al. 2003). Participation in physical activity can improve self-esteem, self-perceptions of competence and body image with a stronger effect for those initially low in self-esteem (Fox, 2000).

Overweight children are less active than their normalweight peers and are less likely to take part in opportunities for physical activity (Trost et al. 2001). Increasing physical activity is an important component of weight management programmes for overweight children (Scottish Intercollegiate Guidelines Network, 2003). In Glasgow the city's Physical Activity Forum (www.glasgowcitycouncil.co.uk/healthycities) has a key target of increasing physical activity levels for children not meeting standard guidelines. Therefore, the Glasgow Physical Activity Forum designed an activity programme, called the B'Active club, to create an environment that would encourage overweight and obese children to become more active and to develop the motivation that is needed both to continue their participation in the programme and to adopt a more physically active lifestyle. In addition, the prevalence of paediatric overweight and obesity in Glasgow is unknown since Scottish prevalence data (NHS Scotland, 2003) did not include Glasgow children. Glasgow has a number of socially deprived areas and a poor health record, therefore the prevalence of childhood overweight and obesity may be higher in Glasgow than the rest of Scotland.

With these issues in mind the aims of the present study were: (1) to determine the prevalence of overweight and obesity in

\footnotetext{
* Corresponding author: Dr Adrienne Hughes, Department of Sports Studies, University of Stirling, Stirling FK9 4LA, UK, fax +44 (0)1786 466477, email adrienne.hughes@stir.ac.uk
} 
primary school children in one school cluster in Glasgow and (2) to use both quantitative and qualitative methods to evaluate a pilot activity programme to provide overweight and obese children with positive experiences of physical activity and the necessary skills to encourage physical activity participation.

\section{Methods \\ Prevalence of overweight and obesity in primary school children in Glasgow}

Participants. The study was conducted in the seven primary schools of the Shawlands New Learning Community in Glasgow between February 2005 and June 2005 and was approved by the University of Strathclyde Ethics Committee. Written informed consent was obtained from all parents/guardians.

Anthropometric measurements. Height was measured to the nearest $0.1 \mathrm{~cm}$ using a portable stadiometer (Leicester; Harlow Printing Ltd, Tyne and Wear, UK). Weight was measured to the nearest $0.1 \mathrm{~kg}$ using previously calibrated electronic scales (SECA; Harlow Printing Ltd). BMI was calculated and converted to standard deviation scores and centiles using the 1990 UK population reference data (Cole et al. 1995). We used epidemiological definitions of overweight (BMI $\geq 85$ th centile), obesity ( $\geq 95$ th centile) and severe obesity ( $\geq 98$ th centile) in order to compare the present data with Scottish (NHS Scotland, 2003) and UK Figs. (Reilly \& Dorosty, 1999). Using these definitions, the expected percentages were $15 \%$ for overweight, $5 \%$ for obesity and $2 \%$ for severe obesity relative to British children in 1990 (Cole et al. 1995).

\section{Piloting a school-based physical activity intervention in overweight and obese primary school children}

Participants. As recommended in current guidelines (Scottish Intercollegiate Guidelines Network, 2003), we used clinical definitions of overweight (BMI $\geq 91$ st centile) and obesity (BMI $\geq 98$ th centile) to identify suitable children for the activity programme. These clinical definitions have high specificity (diagnoses few lean children as overweight or obese) thereby reducing the likelihood of offering treatment to children who are not actually overweight (Scottish Intercollegiate Guidelines Network, 2003). We invited children who were identified as being either overweight or obese using these clinical definitions to take part in the activity programme.

Design of the activity programme. Each school selected a day and time (either lunchtime or after school) for the programme to run. Five schools chose after-school sessions whilst two schools opted for lunchtime sessions. The intervention lasted 10 weeks and each school received one 45 min session per week delivered by qualified coaches.

Duda (2001) recommended that coaches and teachers should develop a mastery climate in their activity sessions to maximise childrens' motivation and enjoyment. Such a climate encourages effort rather than emphasising skill and avoids competitive comparisions between children, such as races to determine who is the fastest. With this in mind, we designed a programme that emphasised effort, learning and improvement in basic motor skills. Enjoyable, age-appropriate activities were chosen by the coaches and included: sports and games, dance, cycling and The Amazing World of Fit Club ${ }^{\mathrm{TM}}$.
Successful experiences were provided through careful assignment of teams, selection of activities and positive reinforcement. Activities were chosen and modified to provide continuous moderate intensity physical activity.

\section{Evaluation of the physical activity programme}

Attendance was recorded at each session. At the end of the class participants rated the session for intensity using the Children's Effort Rating Scale (Williams et al. 1994) and for enjoyment on a scale of $1-10$.

We used qualitative methods to gain a more in-depth understanding of the activity programme. Specifically, eighteen pupils, six parents and five coaches participated in focus groups, while five head teachers completed open-ended questionnaires. Questions were designed to elicit participants' perceptions on the delivery of the programme, and its effectiveness in promoting positive attitudes and behaviours with respect to physical activity and future recommendations. Participants were selected using a convenience sampling strategy (Patton, 2002), which was based on the availability of individuals to attend focus groups. Focus groups were conducted following the recommendations of Berg (2004) and elaboration and clarification probes (Patton, 2002) were used to tease out relevant issues and ensure that responses were interpreted correctly. Following the transcription of focus group discussions, data were inductively content analysed according to the procedures adopted by Scanlan et al. (1991), such that quotations reflecting common threads were clustered together in a hierarchical theme-building process. Head teachers' written responses were also analysed using this method. Trustworthiness procedures (Lincoln \& Guba, 1985) were incorporated into the analysis to ensure that it was methodologically rigorous.

\section{Statistical analysis}

All statistical analyses were conducted using Minitab version 14 (Minitab, Coventry, UK). Categorical data were analysed using $\chi^{2}$ tests. Data are presented as means and standard deviations. The significance level was set at $P<0 \cdot 05$.

\section{Results}

The prevalence of overweight and obesity in primary school children in Glasgow

In total, 1548 out of 1713 pupils participated in the BMI measurement ( $90 \%$ response rate). Non-response was primarily due to absence from school on the day of measurement. Of the respondents, $797(52 \%)$ were male and $751(48 \%)$ were female, $918(59 \%)$ were white and $630(41 \%)$ were black/ ethnic minority. The mean age of the sample was 7.9 (SD 2.0) years and median BMI centile was 67.0 (relative to UK 1990 reference data).

The percentage of children categorised as overweight (BMI $\geq 85$ th centile), obese (BMI $\geq 95$ th centile) and severely obese (BMI $\geq 98$ th centile) was higher than the UK reference standards (Table 1). Results show that $31 \%$ of children were overweight (reference standard 15\%), 19\% were obese (reference standard $5 \%$ ) and $12 \%$ were severely obese (reference standard $2 \%$ ). Table 1 also presents the prevalence of overweight and 
Table 1. Prevalence of overweight, obesity and severe obesity in primary school children*

\begin{tabular}{|c|c|c|c|c|c|c|c|c|}
\hline & \multicolumn{2}{|c|}{$\begin{array}{l}\text { Overweight } \\
\text { (n 486) }\end{array}$} & \multicolumn{2}{|c|}{ Obese (n 295) } & \multicolumn{2}{|c|}{$\begin{array}{c}\text { Severely } \\
\text { obese ( } n \text { 192) }\end{array}$} & \multicolumn{2}{|c|}{$\begin{array}{l}\text { Total group } \\
(n 1548)\end{array}$} \\
\hline & Mean & SD & Mean & SD & Mean & SD & Mean & SD \\
\hline Age (years) & $8 \cdot 3$ & $2 \cdot 0$ & $8 \cdot 3$ & $2 \cdot 0$ & 8.4 & $2 \cdot 0$ & 7.9 & $2 \cdot 0$ \\
\hline \multirow{2}{*}{ Median BMI centile } & $96 \cdot 8$ & & $98 \cdot 8$ & & 99.5 & & $67 \cdot 0$ & \\
\hline & $n$ & $\%$ & $n$ & $\%$ & $n$ & $\%$ & $n$ & \\
\hline All & 486 & 31 & 295 & 19 & 192 & 12 & 1548 & \\
\hline Boys & 258 & 32 & 169 & 21 & 114 & 14 & 797 & \\
\hline Girls & 228 & 30 & 126 & 17 & 78 & 10 & 751 & \\
\hline White & 282 & 31 & 159 & 17 & 100 & 11 & 918 & \\
\hline Black/ethnic minority & 204 & 32 & 136 & 22 & 92 & 15 & 630 & \\
\hline
\end{tabular}

* Overweight, obesity and severe obesity were defined as $\mathrm{BMI} \geq 85$ th, 95th and 98th centile, respectively.

obesity in boys and girls. The proportion of boys and girls who were overweight was similar $\left(\chi^{2}=0.7, P=0.4\right)$. However, more boys than girls were obese $\left(21 \%\right.$ v. $17 \% ; \chi^{2}=4.9$, $P=0.03)$ and severely obese $\left(14 \% v .10 \% ; \chi^{2}=5 \cdot 5, P=0.02\right)$. The prevalence of overweight was similar in white children compared to black/ethnic minority children $\left(\chi^{2}=0 \cdot 5, P=0 \cdot 5\right)$. However, more black/ethnic minority children were obese $(22 \% \mathrm{v}$. $\left.17 \% ; \chi^{2}=4.4, P=0.04\right)$ and severely obese $(15 \%$ v. $11 \%$; $\left.\chi^{2}=4 \cdot 7, P=0.03\right)$ compared to white children.

Fig. 1 shows that the proportion of children categorized as overweight and obese was higher than UK reference standards in each age group and increased with age. The percentage of overweight children increased from $23 \%$ for 4-6-year-olds to $41 \%$ for 11-12-year-olds (Fig. 1). The proportion of children categorised as obese rose from $14 \%$ for $4-6$-year-olds to $25 \%$ for $11-12$-year-olds. In the 4-6-year-old age group, $8 \%$ were severely obese, with the proportion increasing to $18 \%$ for the 11-12-year-old age group.

Piloting a school-based physical activity intervention in overweight and obese primary school children: quantitative results

The activity programme was offered to 375 (24\%) overweight and obese children identified using clinical definitions

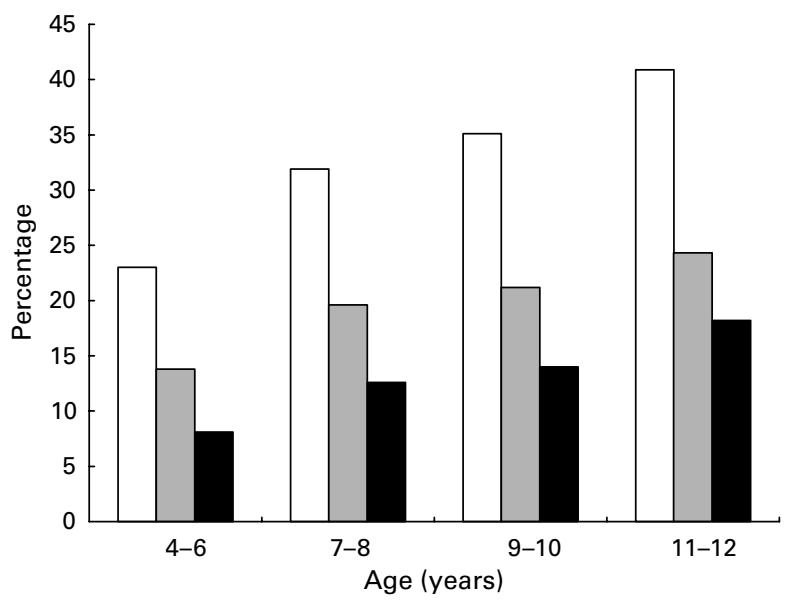

Fig. 1. Prevalence of overweight $(\square)$, obesity $(\square)$ and severe obesity ( by age.
(BMI $\geq 91$ st and 98th centile). Of this group, $209(56 \%)$ were boys and $166(44 \%)$ were girls, 209 (56\%) were white and $166(44 \%)$ were black/ethnic minority.

Of those invited, $38 \%$ (142) participated in the activity programme, seventy-two (51\%) were boys, seventy (49\%) were girls, seventy-six $(54 \%)$ were white and sixty-six (46\%) were black/ethnic minority. When expressed in relative terms, uptake was greater for females $(42 \%)$ than for males $(34 \%)$ and slightly higher for black/ethnic minority children $(40 \%)$ than white children $(36 \%)$. The mean attendance rate over the 10 -week programme was $83 \%$ (range 56-99\%); mean attendance was $80 \%$ for males and $86 \%$ for females (shown in Fig. 2). The average enjoyment rating (scale 1-10) over the 10 -week period was 8 ('really enjoyed the sessions') for boys and 9 ('really loved the sessions') for girls (shown in Fig. 3). Using the Children's Effort Rating Scale, the activity sessions were rated 'very easy' ( 2 out of 10 ) by boys and 'just feeling a strain' (4 out of 10) by girls (Fig. 4).

\section{Piloting a school-based physical activity intervention in overweight and obese primary school children: qualitative findings}

A detailed description of the qualitative findings is beyond the scope of the present paper but is available from the authors. The most commonly cited themes emerging from the analysis are presented, which relate to perceived positive and negative

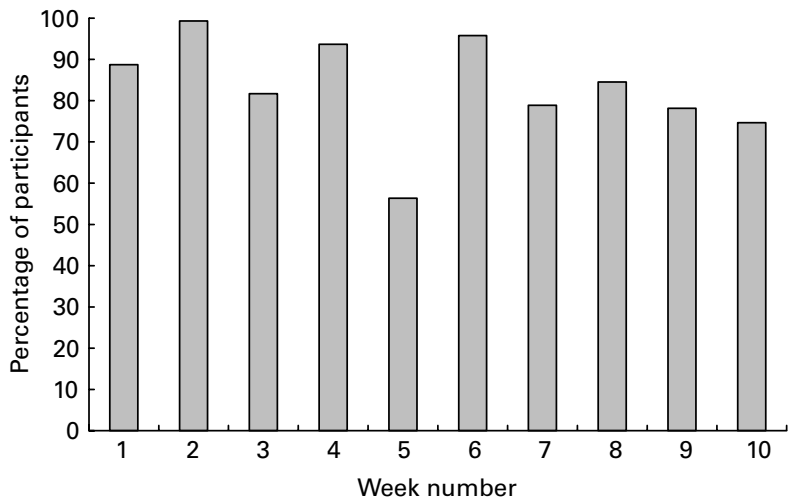

Fig. 2. Weekly attendance of the primary school children at the B'Active programme. 


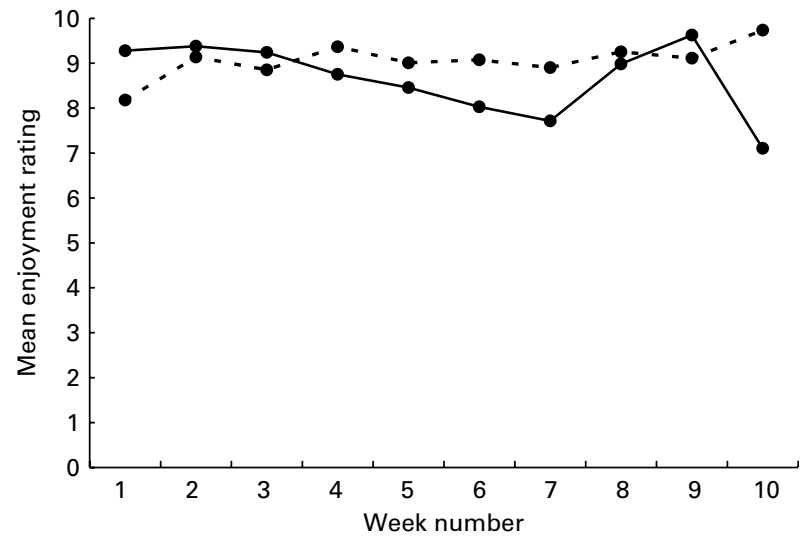

Fig. 3. Mean enjoyment rating of boys $(-\bullet-)$ and girls $(--\bullet--)$ attending the B'Active programme. For details of rating scale, see p. 205.

aspects of the activity programme; physical, psychological and behavioural outcomes; and future recommendations. We have discussed the results collectively as there were many commonalities in the categories of themes that emerged from discussions with each group of participants.

Positive perceptions of the programme included its emphasis on fun, with children consistently reporting enjoying learning new games and making new friends. Parents, teachers and coaches echoed this and typical feedback included: 'I just think that the children really enjoy it, they love it, it's great' [parent] and 'All the kids seemed to really enjoy it and they'd tell you every week that they enjoyed it and you could see in their faces that they were enjoying it' [coach]. The programme raised awareness of dietary and physical activity issues and demonstrated ways of being physically active without the need to excel at sport: "Many children are not interested in being good at sport. This programme has let them see that there are a variety of other ways of being active and so improving their health' [teacher].

Negative perceptions of the programme mentioned by children involved their sense of isolation from peers whilst attending activity sessions: 'I couldn't play with my friends and I wished that my friends were there'. Parents and teachers initially felt that the intervention might lead to children becoming stigmatised and developing body image concerns. Nevertheless, as

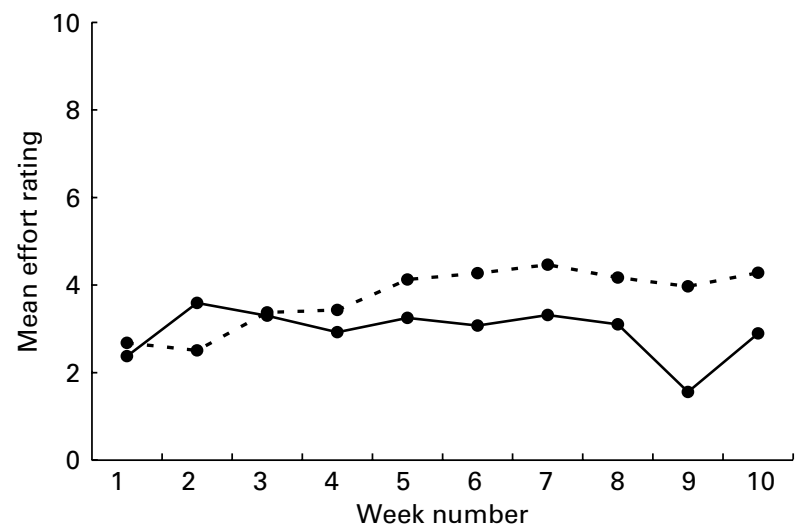

Fig. 4. Mean effort rating of boys $(-\bullet-)$ and girls $(--\bullet--)$ attending the B'Active programme. For details of rating scale, see p. 205. the programme progressed, all participants agreed that it gained a positive reputation within the schools: "word on the street was that it's a cool club to join' [teacher]. There was a general perception that lunch-time activity sessions were 'rushed' and that teachers and parents were not sufficiently involved 'we didn't get the invitation to attend the sessions and I would have made the effort to go, just to be part of it' [parent].

The view that the activity programme produced physical, behavioural and psychological changes was a prominent theme. Physical changes were reported mostly by the children, typical responses included: 'I feel much fitter and that I'm flexible and that I can do more fun things'. Coaches supported this, commenting on improvements in co-ordination skills and other physical abilities. Behavioural changes reported by children and echoed by teachers and parents included increased physical activity levels and willingness to engage in new activities 'I tried it out with my friends because I live in a flat and it seemed quite good learning new games. I learned how to get fit and stuff and now me and my Mum and Dad go walking' [child]. Psychological outcomes were frequently reported, with children typically claiming that the programme helped them feel more confident 'I felt more confident in the games I played 'cause I used to always want to know how to play them ... I feel happier that I went to the B'Active Club and more confident than I used to feel'. Parents, teachers and coaches supported this 'Confidence was the biggest thing definitely, that's the biggest change that was most clearly recognised, like from week one to week ten' [coach].

Future recommendations suggested by teachers and parents included more involvement of parents and teachers, capitalising on previously successful initiatives, making the selection process more discrete, and including all children in the programme to prevent stigmatisation 'It would be good if other children were involved who haven't got a problem but could still be involved in the activities and be conscious of healthy eating so that there's no stigma' [parent]. Finally, it was commonly reported that the programme should include a greater variety and frequency of activity sessions, and all participants strongly believed that the programme should be continued and extended to all other schools in Glasgow: 'It was a very worthwhile project which should become a regular feature of school life across the city' [teacher].

\section{Discussion}

The prevalence of overweight and obesity in primary school children in Glasgow

The present study found that prevalence of overweight and obesity in primary school children in one school cluster in Glasgow was higher than the 1990 UK reference standards for all ages. A recent Scottish study estimated that $23 \%$ of $7-8$-year-olds were overweight and $12 \%$ were obese (NHS Scotland, 2003). These national figures are slightly lower than those in the present study which found that $32 \%$ of 7-8-year-old children were overweight and $20 \%$ were obese; the same BMI cut-offs were used in both studies. The Scottish data also reported that in children aged 11-12 years, $33 \%$ were overweight and $18 \%$ were obese (NHS Scotland, 2003). We found that $41 \%$ of $11-12-$ year-olds were overweight and $25 \%$ were obese. Thus, the prevalence of overweight and obesity in the present study is 
higher than national figures, which may be because Glasgow has a number of socially deprived areas. Secondly, the Scottish survey collected data from 1997 to 1999 , however, the prevalence of childhood overweight and obesity has continued to increase rapidly leading to even higher prevalence of overweight and obesity now.

Previous studies indicate that the prevalence of paediatric overweight and obesity is high in the UK and that the problem is more marked in Scotland than in England (Reilly \& Dorosty, 1999; Jebb et al. 2003). The prevalence of overweight and obesity among children has increased rapidly over the past 20 years in many countries (Lobstein \& Frelut, 2003). However, comparison of prevalence rates among countries is problematic because different methods have been used to define overweight and obesity in children, and there are differences in the age of the samples and the timing of the surveys (Lobstein \& Frelut, 2003). Nevertheless, the highest percentages of paediatric overweight and obesity appear to be in North America, the UK and southern Europe, although prevalence rates in northern European countries are growing toward rates typical of southern Europe (Lobstein \& Frelut, 2003). The reasons for regional differences are not entirely clear at present. Paediatric obesity has significant health risks in childhood and is very likely to persist into adulthood causing increased morbidity and mortality (Reilly et al. 2003). Thus, given the high and rising prevalence of paediatric obesity in many countries and the substantial health burden, interventions to prevent and treat overweight and obesity in youth are urgently required. A recent study (Wardle et al. 2006) found that persistent obesity is established before age 11 , suggesting that efforts should target pre-school and primary school children.

We also found that the prevalence of obesity and severe obesity was significantly higher in boys than girls and black/ethnic minority children compared to white children. Data from the USA found that the prevalence of overweight and obesity was higher among African American and Hispanic children than non-Hispanic white children (Strauss \& Pollack, 2001). Although, few UK studies and no Scottish studies have determined the prevalence of overweight and obesity between different ethnic groups, a recent English study found the prevalence of overweight and obesity was higher in Afro-Caribbean and Pakistani girls, and Indian and Pakistani boys than the general population (Saxena et al. 2004). Consistent with the present findings, recent data from the Scottish Health Survey reported that the prevalence of overweight and obesity was higher in boys than girls (Scottish Executive Health Department, 2003).

\section{Piloting a school-based physical activity intervention in overweight and obese primary school children}

Uptake to the B'Active intervention was low, as only $38 \%$ of overweight and obese children participated in the activity sessions. However, this figure is slightly higher than uptake rates (30\%) to other activity programmes currently running in primary schools across Glasgow. There were initial concerns from parents and teachers that the programme may lead to children becoming stigmatised and developing body image concerns, which may have affected uptake to the programme. Targeting overweight children without creating stigma remains a challenge to health promoters. However, the qualitative evaluation suggested that these concerns were alleviated by the club's emphasis on fun and the programme gained a positive reputation within the schools as it progressed. In addition, despite these initial concerns, quantitative results suggest that the children really enjoyed participating in the club and attendance rates were high $(>80 \%)$ throughout the programme, with the exception of a school holiday during week 5 .

Uptake to the programme was higher for girls and black/ ethnic minority children than boys and white pupils. This can be viewed as a positive outcome as physical activity levels tend to be lower in these groups. Whilst the qualitative evaluation highlighted problems with lunch-time sessions relating to time constraints, the inclusion of lunch-time sessions in the programme may have helped to increase uptake in black and ethnic minority children, as many of these children have to attend organised religious activities after school.

The present programme was designed with a 'mastery climate' in mind, as recommended by Duda (2001). Such a climate maximises childrens' motivation and enjoyment by encouraging effort rather than emphasising skill and avoids competitive comparisons between children. Parents and teachers felt that our programme was successful at encouraging children to engage in physical activity without the need to be good at sport. Results also indicate that children enjoyed taking part in the activity sessions and reported that the programme was fun. Therefore, our plan to create a mastery climate was successful.

Overweight and obese children are more likely to show signs of psychological distress (Reilly et al. 2003), such as low self-esteem and confidence, therefore this group may benefit most from an activity intervention. Results from the qualitative evaluation suggest that enhancing childrens' selfconfidence was a key benefit of the programme. The intervention also produced physical changes such as improvements in fitness and co-ordination skills and behavioural outcomes such as willingness to integrate with others, engaging in new activities and being more active outwith school life.

As might be anticipated with a pilot programme, the intervention was subject to some criticism. To maximise support for the programme in the future, implementers may wish to liaise more with teachers and parents, consider ways to reduce concerns about children being stigmatised and offer the programme to all children regardless of weight status. Overall, views of the initiative were very positive and there was compelling support for its continuation, as this quote encapsulates: 'I really do think it should be continued. I'm quite passionate about this because I think that children do need to get more exercise and they do need to be aware of healthy eating' [parent].

The frequency and duration of the pilot intervention was not sufficient to impact on obesity status and physical activity or to determine long-term enjoyment and attendance at the programme. Therefore, a more robust study design with a longer, more intense intervention is required to evaluate the effect on weight, physical activity and on long-term programme compliance. However, the pilot programme was successful in giving overweight and obese children an opportunity to engage in physical activity in a fun, supportive environment, which increased their self-esteem and confidence. Future research should determine whether participation in such programmes influences their physical activity levels in a wider sense (e.g. by improving their attendance at physical education) and thereby potentially contributing to a reduction in obesity. 
In conclusion, the present study shows that the prevalence of overweight and obesity is high in primary school children in Glasgow. Uptake to the programme was suboptimal, targeting overweight children without creating stigma remains a challenge to health promoters. As the uptake was greater for girls and black/ethnic minority pupils, it would appear to be an appropriate means of engaging these target groups. For those who participated, the activity programme was successful in terms of attendance, enjoyment and improving the psychological and physical well-being of overweight and obese children.

\section{Acknowledgements}

We would like to thank the Glasgow Physical Activity Forum steering group for their guidance and support throughout this project. This project was funded by the Big Lottery Fund.

\section{References}

Berg B (2004) Qualitative Research Methods for the Social Sciences, 5th ed. Boston, MA: Allyn and Bacon.

Cole TJ, Freman JV \& Preece MA (1995) Body mass index reference curves for the UK, 1990. Arch Dis Child 73, 25-29.

Duda JL (2001) Achievement goal research in sport: pushing the boundaries and clarifying some misunderstandings. In Advances in Motivation in Sport and Exercise, pp. 129-182 [GC Roberts, editor]. Champaign, IL: Human Kinetics.

Fox KR (2000) The effects of exercise on self perceptions and selfesteem. In Physical Activity and Psychological Well-being, pp. 88-117 [SJH Biddle, KR Fox and SH Boutcher, editors]. London: Routledge.

Jebb SA, Rennie KL \& Cole TJ (2003) Prevalence of overweight and obesity among young people in Great Britain. Pub Health Nutr $\mathbf{7}$, $461-465$.
Lincoln YS \& Guba EG (1985) Naturalistic Inquiry. Beverly Hills, CA: Sage Publications.

Lobstein T \& Frelut ML (2003) Prevalence of overweight among children in Europe. Obes Rev 4, 195-200.

NHS Scotland (2003) Quality Improvement Indicators: Childhood Obesity. NHS Quality Improvement Scotland, Edinburgh.

Patton MQ (2002) Qualitative Research and Evaluation Methods, 3rd ed. Thousand Oaks, CA: Sage Publications.

Reilly JJ \& Dorosty AR (1999) Epidemic of obesity in UK children. Lancet 354, 1874-1875.

Reilly JJ, Methven E, McDowell ZC, Hacking B, Alexander D, Stewart L \& Kelnar CJH (2003) Health consequences of obesity. Arch Dis Child 88, 748-752.

Saxena S, Ambler G, Cole TJ \& Majeed A (2004) Ethnic group differences in overweight and obese children and young people in England: cross sectional survey. Arch Dis Child 89, 30-36.

Scanlan TK, Stein GL \& Ravizza K (1991) An in-depth study of former elite figure skaters: III. Sources of stress. J Sport Exerc Psychol 13, 103-120.

Scottish Executive Health Department (2003) Scottish Health Survey. www.scotland.gov.uk.

Scottish Intercollegiate Guidelines Network (2003) Management of Obesity in Children and Young People. SIGN Publication no. 69. Edinburgh: SIGN.

Strauss RS \& Pollack HA (2001) Epidemic increase in childhood overweight 1986-1998. JAMA 286, 2845-2848.

Trost SG, Kerr LM, Ward DS \& Pate RR (2001) Physical activity and determinants of physical activity in obese and non-obese children. Int $J$ Obes 25, 822-829.

Wardle J, Brodersen NH, Cole TJ, Jarvis MJ \& Boniface DR (2006) Development of adiposity in adolescence. Five year longitudinal study of an ethnically and socioeconomically diverse sample of young people in Britain. Br Med J 332, 1130-1135.

Williams JG, Eston R \& Furlong B (1994) CERT: a perceived exertion scale for young children. Percept Mot Skills 79 (3 Pt 2), 1451-1458. 